\title{
A TÉCNICA COMO EXPRESSÃO GEOGRÁFICA DAS DETERMINAÇÕES HISTÓRICAS DO TRABALHO
}

\section{The technique as a geographic expression of the historical determinations of labor}

\author{
Elias Lopes de Lima \\ Prof. Adjunto do Departamento de Geociências da UFJF \\ elias.lopes@ufjf.edu.br
}

Artigo recebido em 17/08/2016 e aceito para publicação em 01/06/2017

DOI: $10.12957 /$ tamoios.2017.25145

\section{Resumo}

O presente texto põe em debate o caráter histórico-geográfico da técnica manifestado na sua relação com o trabalho e, por conseguinte, alguns conteúdos subjacentes à reprodução da sociedade capitalista. Tal apanhado compõe uma base de sustentação ontológica para se estabelecer correlações entre: a história e a geografia, no campo disciplinar; o tempo e o espaço, no plano epistemológico; a alienação e a razão instrumental, na esfera ideológica; e, por fim, as classes sociais e os gêneros de vida de regime de reprodução comunitário, no domínio das práticas sociais. Compete-nos inferir que o trabalho confere uma historicidade à técnica, ao tempo que esta retribui uma geograficidade ao trabalho, por meio de suas contraditórias implicações com o desenvolvimento capitalista.

Palavras-chave: técnica; trabalho; classes sociais; gêneros de vida.

\begin{abstract}
This current article establishes a debate on the historical-geographic aspect of the technique expressed towards its relationship with labor and consequently some underlying contents in the reproduction of the capitalist society. Such a compilation provides an ontological foundation support in order to establish correlations between: History and Geography in regard to the discipline field; time and space in regards to the epistemological field; alienation and instrumental reason to the ideological sphere; and finally, social classes and life genres of community reproduction regime in the social practice domain. It is up to us to infer that labor gives technique a historicity while in return, it grants labor a geographical look through its contradictory implications with the capitalist development.
\end{abstract}

Keywords: technique; labor; social classes; life genres. 


\section{INTRODUÇÃO}

A técnica é um dos meios pelo qual, epistemologicamente, a geografia tenta superar a compreensão antinômica de tempo e de espaço cindida pela teoria do conhecimento para, com isso, depreender o teor histórico da produção do espaço. A incorporação da técnica ao discurso geográfico possibilitou que o tradicional enfoque da relação homem-meio se desdobrasse na abordagem da relação sociedade-espaço (GEORGE, 1968; MOREIRA, 2008), autorizando reconhecer o espaço geográfico como um meio histórico-produzido.

Não obstante, um dos problemas mais recorrentes entre as mais variadas abordagens acerca da técnica em geografia é que, a despeito de sua vocação histórica expressa no registro das formas da paisagem legadas pelas formações sócio-espaciais pretéritas, ela é frequentemente tematizada sem qualquer paridade histórica e segundo uma abordagem meramente instrumentalista e espacializante: "um discurso que dispensa a leitura crítica do desenvolvimento histórico seguido pela técnica", como parece lamentar Moreira (2004, p. 26).

Nesses termos, não é difícil que a técnica seja restrita aos aspectos funcionais e utilitários de uma cultura, como fazem, entre outros, alguns estudos culturais ao olvidarem o teor histórico dos gêneros de vida, concepção esta a que a técnica estaria organicamente relacionada. Esse desapego à historicidade da técnica se deve, em parte, a uma total negligência em relação à atividade prática vital da reprodução humana: o trabalho. Ao relegar o trabalho ao segundo (ou a nenhum) plano, não se compreende as determinações históricas e geográficas do modo de produção social hegemônico e das contradições que lhe são inerentes. Com isso, limita-se a técnica a um complexo instrumental, uma entidade com fins e intencionalidade próprios, reduzindo-se, por fim, a própria concepção de Cultura (a inicial maiúscula é proposital) a um fenômeno anistórico.

O presente texto põe em debate o caráter histórico-geográfico da técnica manifestado na sua relação com o trabalho e, por conseguinte, alguns conteúdos subjacentes à reprodução da sociedade capitalista. Tal apanhado compõe uma base de sustentação ontológica para se estabelecer, na primeira seção deste artigo, correlações entre: a história e a geografia, no campo disciplinar; o tempo e o espaço, no plano epistemológico; a alienação e a razão instrumental, na esfera ideológica, e, por fim, as classes sociais e os modos de existência de regime de reprodução comunitário, no domínio das práticas sociais.

Um desdobramento dessas primeiras considerações aponta, na seção seguinte, para a atualidade do conceito de gênero de vida enquanto um correlato do meio técnico-científico informacional. Esta constatação, contudo, não se sobressai pela originalidade. Moreira (2005, 2007) já havia estabelecido uma relação seminal entre o conceito de gênero de vida e o de meio técnico-científico informacional, fazendo-os interagir através da noção de sociabilidade, de Maximilian Sorre.

Interessa-nos, todavia, acrescentar que a presumível atualidade dos gêneros de vida está implícita na concepção de meio técnico-científico informacional não somente em razão de um progressivo incremento instrumental ou da sucessão dos meios técnicos, como ocorreu a Milton Santos (1996). Trata-se, antes, de compreender que o trabalho (certamente, a forma primeira de sociabilidade) confere uma historicidade à técnica e, por analogia, aos gêneros de vida por sua implicação contraditória com o modo de produção capitalista. Dialeticamente, a técnica e os modos de existência derivados das condições geográficas dispostas aos grupamentos humanos retribuem uma geograficidade às relações de produção expressas na contradição capital-trabalho. 


\section{TÉCNICA E TRABALHO COMO CATEGORIAS ONTOLÓGICAS}

Há uma longa tradição na história do pensamento geográfico que se ocupou de destacar a importância da técnica na organização do espaço: de Paul Vidal de La Blache a Milton Santos, a técnica se estabeleceu como um tema eminentemente geográfico. O que não significa admitir que outros campos do conhecimento se furtaram de problematizá-la, dentre os quais, para mencionar algumas contribuições notáveis, se destacam os trabalhos de: Marcel Mauss e George Balandier, na antropologia; Lewis Mumford, na história; Jurgen Habermas, Gilbert Simondon e Martin Heidegger, na filosofia.

Em geografia, contudo, a técnica tem um papel lapidar na produção do espaço, este que é um produto da práxis humana. Ela atua na progressiva diferenciação e complexificação das escalas espacio-temporais, preenchendo os vazios geográficos de formas objetivas como uma espécie de pretora dos arranjos espaciais e da modelação das paisagens. Afinal, técnicas não são "práticas adaptativas" às condições dispostas pelo meio geográfico, como prescreve a tradição lablachiana dos gêneros de vida? Não seria a técnica o "meio" por excelência de intervenção e, portanto, de transformação no quadro natural, logo, mais uma vez, de produção do espaço geográfico, como sugere a não menos admirável contribuição de Milton Santos $(1978,1996)$ ?

Não obstante, é paradoxal atestar que a própria evolução da técnica a destituiu de historicidade quando seu aparato instrumental, convertido em razão instrumental, conquistou uma suposta autonomia do homem - o suficiente para reduzir o seu metabolismo com a natureza a uma dicotomia expressa na separação entre natureza e sociedade. Parte desse imbróglio deve-se ao fato de que a técnica serviu de incremento ao trabalho, permitindo instrumentalizá-lo de tal maneira ao ponto de substitui-lo em suas manifestações mais regulares e rotineiras.

Pierre George $(1968,1969)$ já havia destacado uma implicação existencial entre técnica e trabalho (BITETI, 2003; MOREIRA, 2008). "O trabalho é para ele [George] a mediação da relação do homem com o meio. Uma relação por sua vez mediada pela técnica", recorda Moreira (2008, p. 153). Porém, a progressiva liberação do trabalho por referência ao aprimoramento histórico da técnica é frequentemente confundida com uma emancipação em relação à natureza, embora reflita, com assaz efeito, o estado de alienação em face da relação antinômica entre sociedade e natureza.

A emancipação em relação à natureza sempre foi uma obsessão humana, notadamente da civilização ocidental-moderna. George (1969, p. 31, 32) reconhece, nesses termos, que "o espaço aparece ao mesmo tempo como criação humana e dado natural. Esta criação vai se liberando cada vez mais dos dados naturais à medida que as técnicas aplicadas à domesticação do espaço vão se tornando mais refinadas”. A controvérsia dessa assertiva, vale notar, reside no fato de que algumas das mais avançadas nações em termos tecnológicos, como é o caso dos EUA, mantêm uma extrema dependência das fontes de energia fóssil e de outros recursos naturais. Os motivos que conduzem os geógrafos a aceitarem uma "verdade técnica" expressa em uma razão instrumental concorrem, ainda que indeliberadamente, para o estabelecimento de uma noção abstrata e universalista de liberdade e emancipação em estreita relação com as transformações históricas do trabalho.

O complexo de transformações por qual passa a sociedade e, por analogia, o espaço geográfico, exige que se avalie a técnica sob o ponto de vista das determinações históricas e sociais, ou seja, a partir de uma situação geográfica que implique, de fato, a indissociabilidade entre tempo e espaço. Sendo, ao mesmo tempo, o modo como se produz algo e os meios (os instrumentos) de trabalho, a técnica atua como um meio de interação (um dado mediador) entre os acontecimentos históricos e a realidade geográfica. Não por acaso, Santos (1996, p. 
32) a considera efetivamente um meio geográfico. Evidencia-se, assim, que o progressivo aperfeiçoamento da técnica está por trás de todo o complexo de determinações históricas, o que nos autoriza a considerar tais acontecimentos, igualmente, como determinações geográficas.

Quais seriam, nesses termos, os marcos históricos e geográficos que consubstanciam o teor ontológico da técnica e do trabalho? O trabalho é uma prática vital e imprescindível para a reprodução da vida, sendo a principal atividade responsável pela relação metabólica entre o homem e a natureza (MARX, 2013 [1867]). Ele é o meio pelo qual ao transformar a natureza, impulsionado pela necessidade imperiosa de sua reprodução existencial, o homem transforma sua própria natureza, o que equivale dizer, transforma seu ser e sua representação acerca de si e do real.

Esta concepção de trabalho como externação metabólica da vida é preferencialmente chamada por Arendt (2004) de labor. Decorre que a filósofa alemã compreende o labor como técnica primeira, uma intervenção implicada diretamente no plano da legalidade prática expressa na satisfação da necessidade e, indiretamente, no plano da legalidade ética expressa na liberdade.

Mas técnica não é exatamente trabalho: não são sinônimos e tampouco redutíveis entre si. Ambos, porém, são dimensões da práxis, ou melhor, são domínios práticos que se implicam e se ressignificam entre si, compondo um modo de ser da práxis no curso da hominização do homem e da produção do espaço geográfico. E disso se infere suas respectivas qualidades de categoria ontológica.

Com efeito, a técnica potencializa e maximiza o trabalho, logo, ela também impulsiona a práxis, isto é, a relação segundo a qual transformamos a nossa consciência ao transformar a natureza, o que equivale, em última análise, a produzir espaço. Muito embora, a técnica também limite o trabalho ao se impor como um atributo instrumental orientado para fins específicos e alheios ao homem comum, alienando-o, portanto, de suas faculdades criativas e transformadoras.

Mas, em certo sentido, foi a técnica que propiciou o sobretrabalho, de maneira a provocar, em algum momento no curso do desenvolvimento das relações de produção, o acúmulo de excedentes e, por conseguinte, o surgimento da propriedade privada, viabilizando as bases para a emergência do modo de produção capitalista.

É óbvio que a propriedade privada de bens materiais diversos precede em muito a sociedade capitalista. $\mathrm{O}$ que o crescente volume de excedentes propiciado pela técnica e sua consequente apropriação (por outrem que não o trabalhador) requer é um tipo de propriedade privada especial: a propriedade privada dos meios de produção, de modo que esta subordine as relações de produção, incluindo a força de trabalho.

Para tanto, vai concorrer uma crescente instrumentalização do trabalho, a qual contribui não apenas para o aumento da produtividade, mas também para a alienação do trabalho, do produto do trabalho e, em última análise, do próprio trabalhador. Há, com efeito, um condicionamento mútuo entre os instrumentos de trabalho e a troca especulativa dos excedentes de produção: um aumento qualitativo na escala de produção.

Uma fundamental "distinção entre objeto de trabalho e instrumento de trabalho (que de modo mais geral é uma distinção entre aquilo que é trabalhado e como é trabalhado)" seria realçada por Quaini (2002, p. 72) ao colocar em causa os efeitos do processo de acumulação primitiva do capital. Arendt (2004, p. 134) explica que

nenhum trabalho pode ser reproduzido sem instrumentos: o aparecimento do homo faber e o surgimento de um mundo de coisas, feito pelo homem, são, na verdade, contemporâneos da descoberta de instrumentos e ferramentas. Do ponto de vista do labor, as ferramentas reforçam e multiplicam a força humana até quase substituí-la, 
como ocorre em todos os casos nos quais as forças naturais, como os animais domésticos, a força hidráulica ou a eletricidade, e não coisas materiais, são domadas pelo homem.

A instrumentalização do trabalho aumentaria, portanto, o excedente (produto este cada vez mais estranho ao trabalhador), o que repercutiria no surgimento da propriedade privada como expressão mais acabada do produto do trabalho alienado. Vale notar que tanto a progressiva instrumentalização do trabalho quanto o aumento do excedente respondem, a partir da abjudicação da consciência e de toda sorte de reificações, por uma demanda gerada pela propriedade privada, e não necessariamente o contrário. Não obstante, essas implicações dialéticas impulsionaram, no curso da história, uma crescente complexificação da divisão do trabalho e do estabelecimento de um horizonte objetivo de teor universalista sem precedentes: o capitalismo.

A emergência da propriedade privada dos meios de produção instaura uma nova conotação na relação liberdade-necessidade (ou, ainda, sociedade-natureza, sujeito-objeto), porquanto se evidencia que o grau de liberdade alcançado no curso da história é reservado a pequenos segmentos da sociedade, isto é, a um sujeito de tipo específico que se apropria do excedente produzido, enquanto priva a maior parte de qualquer gozo de liberdade. Quando muito, a liberdade comparece para os estratos subalternizados sob a forma reificada do trabalho livre, extremamente comprometida com os efeitos tanto da alienação em relação à natureza quanto da alienação das qualidades criativas do sujeito.

Com a progressiva expansão e complexificação da divisão do trabalho, no interior da qual o trabalho de um se tornaria atividade útil para outros (VÁZQUEZ, 2007), o trabalho alienado tornar-se-ia a mais universal forma de trabalho particular: o trabalho livre (no seio do qual o ideal de liberdade hipostasiado pela moral burguesa é a pedra angular), a despeito de coexistir e mesmo interagir com uma série de outras formas específicas de exploração do trabalho (escravo, servidão por dívida, doméstico etc.). A ideológica valoração universal da propriedade privada solapa o trabalho, alçando-o igualmente como equivalente geral e abstrato na forma do trabalho livre. Tal ardil impossibilita que se apreenda os conteúdos essenciais da realidade objetiva (senão como formas-aparência), privando o trabalhador de exercer seus próprios poderes essenciais, isto é, sua qualidade de agente criativo e transformador.

Uma vez que não lhe resta outro meio de assegurar a sobrevivência (pois os meios de sua reprodução lhe foram expropriados) e que a força de trabalho torna-se livre, o trabalhador, que a princípio é seu único e legítimo proprietário, pode dispor dela como quem dispõe de qualquer outro bem. Ao alienar sua força de trabalho, o trabalhador aliena não somente sua capacidade de produzir bens de consumo, mas também parte considerável de sua qualidade criativa e transformadora, a substância de seu ser. O que implica em renunciar, sob certa medida, de sua capacidade de aceder os conteúdos indefinidos e reificados de uma natureza socialmente produzida (em outras palavras, de um espaço e de um tempo socialmente produzidos). Com isso, abdica-se, em parte, dos meios que permitiriam ao trabalhador superar seu condicionamento e sua subordinação às relações capitalistas.

Ao ser convertido em propriedade de outrem, o produto do trabalho contribui para a alienação do próprio trabalhador, pois sucede em sua atividade um processo em sentido avesso ao da objetivação, porquanto o produto de seu trabalho, ao invés de consistir num objeto de sentido, converte-se numa coisa que não lhe diz respeito, com a qual não tem afinidade e identidade. Uma vez que o trabalho se torna exterior ao homem (MARX, 2004 [1844]), também o seu produto assume uma forma que lhe é estranha; ou, antes, o produto de seu trabalho não possui uma forma, não é um objeto e sim uma coisa. Isto é, ele não pertence 
ao trabalhador, pois sua conversão em coisa e, de imediato, em propriedade privada de outrem expurga, como que em sacrifício da vida, o teor criativo de seu espírito. O trabalhador não se vê no objeto produzido por si mesmo, não o possui, pois este objeto é propriedade privada de terceiros, bem como sua própria força de trabalho e todos os instrumentos e meios necessários para a sua produção.

Aos poucos, a propriedade privada torna todo o corpo social passível de alienação, isto é, torna-o alienável, sujeito à troca (o caráter material da alienação), de modo que o próprio homem, na qualidade de provedor da força de trabalho, torna-se também alienável, isto é, propenso a alienar (vender ou trocar) sua força criativa, e disso deriva uma alienação no plano da consciência. Está claro aqui que "o que pode se dizer de qualquer objeto material convertido em mercadoria também vale para cada objeto social e mental", reconhece Lefebvre (2006, p. 43). Smith (1988, p. 82) também sustenta que "a alienação do trabalhador implica, junto com uma alienação estritamente material, em uma certa alienação da consciência”, pois ao alienar sua força de trabalho, o trabalhador está alienando, junto, a sua força criativa, a sua essência vital.

Sob a determinação da alienação, a propriedade privada se torna, sob certos aspectos, um "sujeito" que personifica o processo de produção, uma vez que passa a impor ao homem um alheamento em relação às "coisas" que ele próprio produz, fazendo do trabalho alienado sua essência subjetiva (MARX, 2004, p. 99). Nesses termos, a propriedade privada convertese em produto de si mesma, um objeto estranhado (uma coisa) para o homem.

Se o produto do trabalho se torna uma propriedade privada e, portanto, uma coisa para o trabalhador, também o comando da atividade fundamental para sua existência (o trabalho) lhe é privado na medida em que ela própria (a propriedade privada) se converte em mercadoria. Sob este prisma, é o trabalhador quem se converte em um objeto, já sob a determinação reificadora da propriedade privada. $\mathrm{O}$ fato de a remuneração que percebe estar associada ao tempo de trabalho executado, e não ao produto de seu trabalho, conduz para a sua mais completa alienação. Este quadro é ainda agravado pela evidência de que o seu trabalho é apenas um elo de uma cadeia de produção, de modo que seu esforço não se presentifica em um produto palpável e identificável, porquanto não lhe resta nenhum meio de dar uma forma objetiva ao conteúdo dessa experiência.

Aqui também a técnica é chamada a intervir, sobretudo no que concerne à difusão, na atual conjuntura histórica, de uma racionalidade instrumental. Fruto do casamento entre ciência e técnica a partir da última quadra do século XX, a razão instrumental assume, num contexto técnico-científico informacional (SANTOS, 1996, p. 145), uma intencionalidade que impõe certas ações e condutas específicas aos indivíduos em seus afazeres cotidianos. Num meio geográfico impregnado de uma razão instrumental de extrema carga utilitarista, somos impelidos a um agir pré-concebido dada a extrema carga intencional e funcional dos objetos técnicos. A racionalidade instrumental concorre, pois, para a alienação nos mais corriqueiros gestos e atitudes, geralmente imposta de fora para dentro, isto é, a partir do imperativo de uma escala de concepção das ações sobre a escala de impacto das ações (SANTOS, 1996, p. 121).

Ao potencializar exponencialmente a força de trabalho, ampliando o excedente produzido e expropriando-o de seu real produtor, a instrumentalidade técnica também concorre para a alienação do trabalhador acerca do fruto de seu próprio trabalho, colaborando, por analogia, para o cerceamento das qualidades criativas e transformadoras do homem. Determinação esta agravada pelo fato de que o aparato instrumental orientado para o trabalho conduz à sua reprodução irrefletida, isto é, sua mecanização, se não uma completa liberação do trabalho em face de suas expressões mais regulares e rotineiras. Nesse caso, a razão instrumental contribui, num plano mais amplo de considerações, para a reificação 
(coisificação) da natureza e para a consequente alienação do homem no tocante à reprodução do espaço.

A apropriação privada dos meios de trabalho e, portanto, dos meios de existência do trabalhador constitui um marco histórico da reorientação da relação entre o homem e a natureza e, logo, da produção do espaço geográfico. A suposta dissociação das ações humanas em relação ao espaço, expressa na ainda hoje influente acepção de espaço per se (SOJA, 1993) como um correlato de acepções euclidiana e cartesiana de espaço, conduz à ilusão de que o homem se emancipa da natureza à medida que a técnica se torna mais avançada.

Uma vez que é um produto social, o espaço geográfico torna-se, sob os desígnios de uma razão instrumental, objeto de alienação, e disso se infere a expropriação da terra e a consequente desterritorialização a que foram (e ainda são) submetidos os gêneros de vida camponeses (e mesmo urbanos) e outros regimes comunitários. A liberação da força de trabalho como marco histórico de constituição de um sujeito de tipo muito específico (a classe social) reflete, pois, o seu quadro geográfico: um cenário que não conforma a formação da base territorial do trabalhador, senão como transferência da força de trabalho na consecução de uma divisão territorial do trabalho do tipo cidade-campo, ou seja, a título de desenraizamento e desterritorialização.

No âmago desse processo, a técnica assume uma importância capital. Ela é responsável pela emergência de determinados gêneros de vida, isto é, modos de existências humanos com base em técnicas "adaptativas" transformadoras do meio geográfico, conforme a definição de Vidal de La Blache (2005 [1911], p. 114). No interior e no decurso deste "meio", as determinações geográficas comparecem como condições de reprodução social impostas por um espaço socialmente produzido, acarretando, com isso, uma gama variável de representações. Parte significativa dessas efusões representacionais deriva da forma como a técnica e o trabalho intermedeiam essa reprodução nos mais variados contextos históricos.

\section{A ATUALIDADE DOS GÊNEROS DE VIDA}

Os gêneros de vida são expressões técnicas da relação homem-meio de que tanto se ocupou parte significativa da tradição geográfica. Podem ser interpretados, nesses marcos, como intervenções práticas e adaptativas de determinadas grupos humanos no "meio geográfico" por intermédio de recursos técnicos peculiares à sua forma de reprodução. Entretanto, a complexidade que assume o meio técnico na atual conjuntura requer ampliar essa concepção fisiológica e orgânica por referência a um meio geográfico cada vez mais dinâmico. Os espaços de vivência desses grupos passariam a ser trespassado por verdadeiras linhas de forças de conteúdos variados, demandando um conjunto de relações assimétricas, cujos polos dominantes são exteriores à sua tradicional base de reprodução, o que redimensiona, por fim, essa reprodução.

As distinções entre os gêneros de vida não podem mais ser atribuídas apenas à posição de isolamento na montanha, à clareira de uma floresta, aos regimes de cheias e vazantes de uma planície de inundação, à escassez dos recursos ou às adaptações às intempéries climáticas, como ocorria a Vidal de La Blache (2007 [1902], p. 125). No passado, os "modos de vida do homem na superfície terrestre, modos de agrupação, consistiam em uma simples descrição considerada principalmente como um conhecimento de caráter utilitário e prático ou como uma imagem pitoresca dos costumes e diferentes maneiras de ser dos povos", recorda Demangeon (1956, p. 12), um dos ilustres herdeiros do grande mestre francês.

Sob essa perspectiva utilitarista, a região lablachiana se estabeleceria como o conceito ordenador que ditaria um princípio de unidade à profusão de fenômenos geográficos, circunscrevendo os limites locais da dinâmica de reprodução dos gêneros de vida. A 
personalidade regional condiz, nesses termos, com a personalidade paisagística e locacional dos modos de existência desses grupamentos humanos, preenchendo de geograficidade sua cultura e sua história. Le Bossé $(2004$, p. 164, 165) recorda que

essa perspectiva geográfica, que enraíza conjuntamente a identidade do lugar e do homem habitante na profundidade da história do grupo e de sua relação com o ambiente, estava ainda fortemente associada a perspectivas naturalistas e não dava conta da irrupção da modernidade, especialmente da vida urbana, em sociedades congeladas em seus traços tradicionais.

Para os padrões de hoje, contudo, restringir o fenômeno geográfico à escala local, sem entrever a tessitura de vetores multiescalares e fenomenais que se lhe atravessam, repercute, igualmente, em uma restrição de sentido geográfico das correlações de forças que condicionam e autorizam essa complexa dinâmica. É claro que alguns gêneros de vida permanecem, sob certos aspectos, como há séculos. Mas é inegável que ocorreu uma mudança de conteúdo na escala de condicionalidade do meio geográfico, sobretudo se se considerar a expansão das contradições do sistema capitalista a uma escala global, derivando, daí, algumas "adaptações práticas" ou, se quiser, algumas ações estratégicas e mediadoras por parte de muitos desses grupos.

Poder-se-ia arriscar dizer que essa propriedade mediadora dos gêneros de vida, e não, exatamente, aquilo que Vidal de La Blache qualificou como uma capacidade "adaptativa" (para nos desviarmos um pouco de seu teor evolucionista), poderia muito bem ser estendida a um meio geográfico caracterizado pelo aumento da circulação de bens, de capitais, de trabalho, de informação e de ordenamentos espaciais em escala global.

$\mathrm{O}$ crescente avanço da sociedade moderna urbano-industrial, atrelado à expansão das contradições do modo de produção capitalista a uma escala planetária, parece, aparentemente, dificultar a identificação dos gêneros de vida regrados pelas condições geográficas descritas por Vidal de La Blache e seus contemporâneos. O que levaria muitos autores, dentre os quais Paul Claval (2011, p. 137, 141, 257) e Le Bossé (2004, p. 164, 165, conforme enxerto acima), a aceitarem que o conceito de gênero de vida não se aplica às sociedades modernizadas pela industrialização e pelo crescimento urbano.

O presumível desuso da noção de gênero de vida mediante o desenvolvimento urbanoindustrial e a expansão planetária do capital estaria relacionado ao próprio declínio do "paradigma" de geografia que a sustentava: o da geografia regional clássica. Sua concepção tradicional, supostamente, não encontraria meios de sustentação no "paradigma" geográfico do espaço na qualidade de um meio histórico-produzido.

Se de fato é a interdependência entre um meio geográfico e o gênero de vida que determina a estabilidade deste último, como sustenta a leitura tradicional, supõe-se que a crescente velocidade, fluidez e inconstância das relações características do espaço urbano na atualidade, produto de um meio geográfico cada vez mais instrumentalizado, compromete a permanência dos gêneros de vida de regime comunitário. George (1969, p. 34) faz notar, inclusive, que "os vínculos com o espaço se tornam cada vez mais abstratos, à medida que a economia se torna mais desenvolvida e diversificada". Essa constatação poderia implicar um suposto esgotamento da noção de gênero de vida, como se precipitou em avaliar Claval, Le Bossé e alguns outros analistas.

Entretanto, Max Sorre (1984, p. 122), um dos primeiros geógrafos a problematizar os gêneros de vida em ambientes urbano-industriais, não parece estar convencido desse esgotamento: 
Gêneros de vida dissolvem-se sob os nossos olhos. Outros se organizam, conquistam espaço e impõem-se aos homens. Às vezes, hesitamos em reconhecê-los, ou porque, situados no meio do rio, distinguimos mal as suas margens, ou porque a aceleração das mudanças de todas as formas de vida - devido à penetração dos dados científicos em todos os ramos da atividade - constrange a consolidação de complexos de hábitos, de sentimentos e de idéias [sic], ou porque um véu de uniformidade mascara as diferenças. Estas subsistem, tanto num plano como noutro, e a tarefa do geógrafo consiste em desvendá-las.

O desvelamento de alguns conteúdos do espaço e a consequente reorientação do paradigma técnico a ele subjacente vêm autorizando a atualidade da noção de gênero de vida, pelo que tudo parece indicar. O impacto do aumento da circulação de bens, de capitais, de trabalho e de informação sobre os gêneros de vida dos mais variados grupamentos humanos no mundo consiste tanto em um fator de dispersão quanto de coesão desses modos de existência.

É claro que esse dinamismo fluído concernente ao conteúdo geográfico do espaço precisa sempre ser relativizado e questionado, principalmente se levarmos em consideração os sujeitos objetivamente implicados: afinal, ele é fluído para quem? Não se trata, contudo, de tão somente questionar a desigual mobilidade entre os homens, senão a subordinação de seus modos peculiares de reprodução à reprodução do modo de produção hegemônico. A depender da escala de análise, já não é prematuro admitir que, de uma maneira ou de outra, todos os gêneros de vida do planeta estariam, potencialmente, implicados na reprodução social de um espaço global (ainda que o seja a título de reserva de mercado), considerando o modo de reprodução desigual da sociedade vigente.

A despeito dos obstáculos para o efetivo acesso às redes de fluxo global por determinados indivíduos, permanece a interdependência ao meio geográfico. Aliás, tais fluxos passam a fazer parte determinante da própria realidade geográfica; passam a constar, eles próprios, como conteúdos do espaço geográfico. Santos $(1978$, p. 174) afirma que alguns vetores de reprodução da vida, "assim como as idéias [sic] de como utilizar o espaço", vêm de fora, de outra escala que não somente à de sua reprodução local.

A reprodução atual dos gêneros de vida é, nesses termos, condicionada por um meio geográfico atravessado por um conjunto de vetores, de relações e de linhas de forças que cingem da escala de concepção das ações à escala de impacto das ações (SANTOS, 1996, p. 121). A tradicional unidade localizacional desses gêneros de vida passa, portanto, a sofrer um ordenamento gestado fora do território, implicando não somente a expropriação de seus recursos como também a incorporação da força de trabalho dos grupos atrelados a esses modos de existência a uma divisão do trabalho de amplitude planetária.

A atualidade da noção de gênero de vida vem acompanhada da restauração, sob novas bases, do conceito de região, o principal expediente metodológico geográfico que lhe prestava subsídio, sobretudo na leitura lablachiana. Sob este aspecto, não se trata mais de apreender a região segundo um recorte espacial cuja escala de ocorrência acataria a uma lógica zonal ou setorial, mas de uma região motivada numa trama em rede de abrangência global atravessada por múltiplos vetores e campos de força (HAESBAERT, 2010). Esta reorientação teóricoconceitual impactaria todo o campo temático e operacional da geografia, reafirmando-a como um importante instrumento de leitura de um mundo sob novas bases ecológicas de sociabilidade e sob o imperativo do novo paradigma técnico-científico produtivo, base do crescente número de fluxos e circulação em redes globais de capital, trabalho, informação, consumo etc.

Para todos os fins, a concretude característica do espaço, incluindo a materialidade herdada das formações sociais precedentes, garante uma permanência relativa aos gêneros de 
vida tradicionais, ainda que sua forma-conteúdo passe a contar com o cruzamento de um semnúmero de situações decorrentes de vetores externos à dinâmica localizacional. Não que os mesmos permaneçam estáticos no tempo e no espaço, reproduzindo as mesmas práticas reprodutivas que os caracterizaram como um modo de existência peculiar expressos numa imagem personalizada da região e da paisagem. A contínua reprodução do espaço geográfico impõe uma plasticidade ao gênero de vida, autorizando transformações em seu conteúdo objetivo: o gênero de vida muda "à medida que a atividade dos homens muda de dependência", explica Sorre (1984, p. 120).

É nesse sentido que podemos depreender as sucessivas transformações desses modos de existências. Às primorosas descrições dos mais variados gêneros de vida tradicionais (camponeses, caçadores, pastores etc.) empreendida por Vidal de La Blache, podem ser acrescidas, a título de mudanças estruturais na reprodução do espaço geográfico, os gêneros de vida urbano-industriais expressos nos traços de Max Sorre. Ambas as caracterizações iriam se desdobrar, por fim, na forma do meio técnico-científico informacional sob a pena de Milton Santos (1996). Disso se infere que o sucessivo aprimoramento da técnica responde, em grande medida, pela mudança das condições de reprodução dos gêneros de vida, já que "a cada evolução técnica corresponde uma nova forma de organizar o espaço" (SANTOS, 1978, p. 108).

A propósito, a evolução dos meios técnicos evocada por Santos (1996, pp. 186-190), segundo a qual um meio natural precederia um meio técnico que, por sua vez, antecederia um meio técnico-científico informacional, corresponde à própria evolução dos gêneros de vida na história. Nesse caso, os gêneros de vida mais tradicionais compilados por Vidal de La Blache, cuja escala de atuação não ultrapassa o arrabalde comunal, correspondem em maior número ao meio natural. Já os gêneros de vida urbano-industriais problematizados por Sorre correspondem, descontadas algumas nuanças, ao meio técnico. Por fim, os modos de existência cada vez mais complexos, surgidos a partir do incremento das tecnologias de informação, da nanotecnologia, da bioengenharia, da reestruturação do regime de acumulação, da divisão internacional do trabalho e da "flexibilização" do trabalho seriam correlatos ao meio técnico-científico informacional evocado por Santos.

É claro que essas disjunções não são rígidas ao ponto desses momentos serem excludentes entre si. Os gêneros de vida que Vidal de La Blache e Max Sorre punham em evidência continuam, sob manifestações matizadas, a vigorar e a desempenhar um papel importante na caracterização múltipla e diversa do espaço geográfico. A abordagem de Sorre, aliás, é o elo entre o conceito de gênero de vida em Vidal de La Blache e os meios técnicos em Santos, incluindo, em ambos os conceitos, um enlace ontológico que alcançará nossos dias. Inspira sua proposição o conceito de sociabilidade, focado na integração das esferas inorgânicas, orgânicas e social através do trabalho. De acordo com Moreira (2005, p. 103), “o gênero de vida e o meio técnico são conceitos geográficos, a que o conceito de sociabilidade vem emprestar o sentido ontológico da formação do homem referenciado no trabalho".

Novamente, a implicação ontológica entre técnica e trabalho, acrescida e mediada pela sociabilidade, está no cerne dessas transformações, sobretudo se considerarmos que a ampliação das contradições do sistema capitalista a uma escala global nas últimas décadas implicou a inserção de inúmeros modos de existência comunitários no circuito global da exploração da força de trabalho. O conceito de meio técnico-científico informacional evoca, assim, a atualidade e a pertinência do conceito de gênero de vida para a análise geográfica a partir da ampliação da escala de atuação dos grupos humanos na produção do espaço.

Uma nova matriz de recursos e de matéria-prima é inaugurada com o advento da informática e, sobretudo, da engenharia genética, alterando, em parte, a base produtiva do capital, que até há poucas décadas estava centrada nos recursos geológicos e mineralógicos 
(MOREIRA, 2005). Atualmente, essa matriz está cada vez mais voltada para a manipulação genética dos recursos naturais em laboratório. O desenvolvimento de uma variedade de cultivares entre muitas culturas e ao longo de incontáveis séculos, decorrentes da relação metabólico-coevolutiva entre homem e natureza, cede vez à produção de cultivares derivados de uma relação mercadológica entre tecnociência e natureza: os cultivares são convertidos em commodities.

O eixo de reprodução da segunda natureza se desloca, assim, dos processos biocenóticos de evolução natural (e, sob certos aspectos, cultural) das espécies para a manipulação de "organismos cujo processo de criação não se dá de modo livre na relação da sociedade com a natureza, mas sim a partir dos laboratórios cada vez mais ligados ao mundo financeiro, industrial e midiático" (PORTO-GONÇALVES, 2008, p. 2). A atenção se volta para as culturas que, ao longo de lentas e laboriosas experimentações de práticas costumeiras de domesticação de plantas e animais, acumularam um cabedal de conhecimentos sobre o manejo dos solos, variações climáticas, aproveitamento medicinal de raízes, plantas, insetos etc.

As populações indígenas e camponesas são portadoras de um acervo cultural extremamente rico, assim como de um enorme conhecimento a respeito da biodiversidade das florestas e demais ecossistemas e, por isso, se constituem em importantes protagonistas para o desenvolvimento de tecnologias de ponta, como a biotecnologia (PORTO-GONÇALVES, 2002, p. 57).

Não é coincidência que os povos da floresta, dentre outros gêneros de vida de regime de reprodução comunitário, ganhem visibilidade no debate em torno do processo de reapropriação social da natureza (LEFF, 2006) a partir do recrudescimento da crise ambiental. Essa complexa combinação de saberes e práticas passa a ser, sob a lógica do novo paradigma produtivo, igualada ao novo modelo de natureza emergente (o da sustentabilidade e da biodiversidade), o que não a impede de ser considerada uma espécie de matéria-prima. Logo, seus possuidores são reduzidos a meros objetos de cobiça de corporações multinacionais, a despeito de esses saberes estarem inscritos em seus corpos, grafados em sua cultura, base de afirmação de seu protagonismo.

Os antigos gêneros de vida que conseguiram sobreviver à expansão da sociedade moderno-capitalista e manter a duras penas alguns de seus traços culturais, antes circunscritos aos limites locais dos territórios de caça, da pesca, de coleta e de seus rituais ancestrais, agora se encontram, de um modo ou de outro, integrados como força produtiva ou, em última análise, como reserva de mercado numa divisão do trabalho globalizada. O nível de especialização requerido por ocasião da incorporação desses grupos ao circuito de reprodução globalizada do capitalismo, forçando a subalternização de sua força de trabalho à ordem social vigente, já seria suficiente para desestruturar todo o ethos societário de gêneros de vida aparentemente ultrapassados para os padrões técnicos e científicos atuais - e assim o foi com muitas dessas sociedades.

Tal incorporação, contudo, não se daria sem resistência. Ao se inserirem, direta ou indiretamente, ao circuito de reprodução global do capital, comunidades indígenas, populações quilombolas, camponeses sem-terra, populações ribeirinhas atingidas por barragens, trabalhadores extrativistas e muitos outros grupos se integram às lutas contra os mecanismos de exploração da força de trabalho, de recursos e de expropriação territorial, bem como os crescentes níveis de desigualdade característicos da sociedade capitalista. O recrudescimento da luta de grupos sociais organizados segundo modos de existência 
comunitários, sobretudo aqueles integrados no sistema capitalista como força de trabalho subproletarizada, confirma-os como outros sujeitos histórico-geográficos.

\section{CONSIDERAÇÕES FINAIS}

No alvorecer da história, o homem transforma (produz), através do trabalho e das técnicas ao seu alcance, a natureza ao tempo em que a converte em espaço geográfico para fins de sua própria reprodução. Assim, ele dá os primeiros passos para a produção de uma natureza socializada ao tempo em que reproduz sua própria natureza humana.

O trabalho e a técnica possuem uma matriz ontológica comum, ambos estão histórica e geograficamente imbricados: a técnica nutre o arco escalar do trabalho, potencializando-o e contribuindo para a complexidade das relações sociais; enquanto o trabalho assume formas particulares e mediadoras (trabalho escravo, servil, comunitário ou familiar, livre) que determinam as práticas adaptativas dos gêneros de vida na produção do espaço.

A indissociabilidade entre tempo e espaço, como se convencionou admitir a partir da renovação epistemológica por qual passou a geografia, é, sob determinados aspectos, correspondente à indissociabilidade entre trabalho e técnica, no âmbito das práticas sociais e da reprodução histórico-geográfica da sociedade. Ambas as relações são revestidas de historicidade, logo, também de geograficidade: de um sentido geográfico de ser que compreende um sentido histórico de estar. Destacando a implicação mútua entre espaço e tempo, Santos (1996, p. 44) argumenta que "é por intermédio das técnicas que o homem, no trabalho, realiza essa união entre espaço e tempo".

A história do trabalho se confunde com a da própria técnica na medida em que tempo e espaço são realidades indissociáveis. O desenvolvimento da técnica está atrelado, junto com o trabalho, ao desenvolvimento das sociedades humanas, correspondendo tanto às suas histórias locais e particulares, quanto à história geral, permitindo, nesse sentido, a consolidação da geografia como uma ciência histórica. A idade histórica da técnica está ligada ao momento em que ela é inserida na sociedade, em que passa a ser utilizada (SANTOS, 1996, p. 47), e é isso o que torna a técnica, expressa nas formas do arranjo espacial, um marco histórico, um testemunho geográfico da projeção qualitativa e escalar das formas e das determinações do trabalho na sociedade.

A técnica estaria, então, para a (re)produção geográfica do espaço como o trabalho estaria para a reprodução histórico-material da sociedade, isto se subentendido o entrelaçamento entre tempo e espaço no edifício histórico-geográfico de significação do real. O corolário da razão instrumental - cuja extrema carga de funcionalidade "sugere" um agir específico por parte dos agentes sociais - é, nesse sentido, o correlato geográfico do paradigma do trabalho alienado em termos históricos.

Façamos uma breve ressalva: é claro que essa imagem consiste apenas em um recurso didático para demarcar o papel da técnica e do trabalho na evolução histórica da produção do espaço. Em realidade, essas distinções não são tão rígidas e arbitrárias, e tampouco técnica e trabalho são prerrogativas, respectivas, das realidades geográfica e histórica. O estudioso, munido dessas categorias (da práxis), poderia, perfeitamente, ajustar os termos de sua análise como melhor lhe convir, desde que não traia a expressão real do fenômeno objeto de sua investigação.

A centralidade do trabalho na produção social e histórica nos impulsiona a evocar o protagonismo das classes sociais, na qualidade de sujeitos históricos da reprodução social. Atualmente, porém, cada vez mais outros estratos sociais, além das classes tradicionalmente vinculadas à reprodução do capitalismo (a burguesia e o proletariado, em especial), passam a se afirmar como sujeitos históricos em face do papel desempenhado na reprodução da 
sociedade capitalista. A indelével associação desses grupos sociais à técnica, em termos de um aparato instrumental potencializador das forças produtivas, convoca-nos a sugerir, nesse caso, a atualidade dos gêneros de vida de reprodução comunitária em seus modos de existência adaptativos a um complexo meio geográfico que, hoje, se distende em uma dinâmica escalar que entrecruza o domínio local e o planetário.

Ora, se a geografia reclama, reiteradamente, a produção social do espaço, nada mais alusivo e coerente que associar essa produção espacial às forças sociais capazes de empreendê-la. E, nisto, não somente as classes sociais, como, também, os mais variados grupos sociais segundo seus gêneros de vida de regime comunitário assumem um papel de destaque. Esse par dialético se desdobra em múltiplas outras manifestações da vida social. Teríamos, assim: i) uma relação entre história e geografia, no âmbito científico-institucional; ii) correlativa a uma relação entre tempo e espaço, no plano epistemológico; iii) alusiva, por conseguinte, a uma relação entre trabalho e técnica, no domínio ontológico; iv) correspondente, por sua vez, a uma associação entre classe social e gênero de vida, no campo da prática social e da reprodução das condições materiais de existência; v) atravessadas, enfim, por uma implicação mútua entre alienação e racionalidade instrumental no domínio da propagação ideológica, de maneira que suas respectivas representações advêm dos limites impostos por tais condições.

É nesse sentido que consideramos a produção social do espaço, manifesta na paisagem e na configuração territorial - mediada pela técnica no curso de reprodução das formações sociais tanto do passado quanto do presente - uma expressão geográfica das determinações históricas do trabalho. Esse dado se torna cada vez mais evidente quando, hoje, os gêneros de vida dos mais diversos cantos do planeta são convocados a se somarem tanto como força de trabalho ao circuito global da produção capitalista, quanto às lutas emancipatórias contrárias a este aparato de exploração.

Wallerstein (2001, p. 79) avalia que, a partir de 1950, os movimentos antissistêmicos passaram a abranger "mais áreas periféricas, mais mulheres, mais grupos 'minoritários' (das mais diferentes definições) e uma parcela maior do setor menos qualificado e menos remunerado da força de trabalho". A integração de um sem-número de grupos sociais com seus modos de existência domésticos e comunitário à cadeia mercantil global, na maior parte dos casos incorporados de maneira precária e não necessariamente devotados exclusivamente à reprodução do capitalismo, autoriza-nos a considerar, portanto, a atualidade do conceito de gênero de vida. Portanto, além da classe operária, uma gama variada gêneros de vida de regime comunitário adere à luta contra as forças hegemônicas da sociedade (LIMA, 2013, 2014), inserindo na pauta de suas reivindicações questões como preservação e autonomia territorial, ambiental, cultural, étnica, linguística, dentre outras demandas político-sociais.

A pertinência do protagonismo desses gêneros de vida no cenário geográfico atual não é fortuita. Deriva do fato de que esses grupos são convocados a transformar, reordenar e ressignificar as formas e configurações sócio-espaciais em uma conjuntura de conflitos ou de crises estruturais e, portanto, de mudanças sistêmicas: econômicas, ecológicas (sobretudo, no que se refere às matrizes energéticas e aos recursos essenciais à manutenção da vida, como a água e a produção de alimentos), epistemológicas, normativo-jurídicas, políticorepresentacionais etc. Cada grupo combina, assim, sua agenda de reivindicações especifica com um objeto de indignação comum a todos os outros: a expropriação da dignidade humana por meio dos processos de desterritorialização e desenraizamento cultural impostos pela expansão capitalista.

As novas tecnologias de informação e comunicação, as quais são ao mesmo tempo um requisito e uma consequência do mercado, estão na base tanto dessa amplitude planetária do capitalismo e do aprofundamento de suas contradições quanto da organização das 
manifestações de insubordinação desses sujeitos. Este dado confirma, mais uma vez, a implicação histórico-geográfica entre técnica e trabalho. A julgar pelo alcance global do capitalismo, supomos que está em trâmite a formação, se não exatamente de uma consciência de classe planetária, pelo menos de um sentimento comum de revolta e contestação contra as injustiças e desigualdades resultantes das práticas de exploração da mais-valia e de acúmulo de riquezas.

Os gêneros de vida de reprodução comunitária estão na linha de frente dessas manifestações de insurgências. Ainda que taxados de sociedades pré-capitalistas, populações tradicionais, comunidades de subsistência, estratos subproletarizados ou seja lá qual a forma que compareça ao discurso dominante, esses grupos e seus modos de existência refratários integram-se, por meio da reprodução desigual do capitalismo, no circuito global da produção, da circulação, da troca e do consumo de mercadorias. Por conta de sua incorporação precária como força de trabalho ou reserva (de trabalho, de recursos e de consumo) no sistema capitalista, eles passaram a engrossar o grito dos oprimidos e dos explorados e a introduzir novas expressões de luta social e política. 


\section{REFERÊNCIAS BIBLIOGRAFICAS}

ARENDT, Hannah. A Condição Humana. Rio de Janeiro: Forense Universitária, 2004. BITETI, Mariane. A geografia do trabalho em Pierre George. Revista Ciência Geográfica. Bauru: AGB Bauru, vol. IX, nº. 3, pp. 233-242, 2003.

CLAVAL, Paul. Epistemologia da Geografia. Florianópolis: Ed. da UFSC, 2011.

DEMANGEON, Albert. Problemas de Geografía Humana. Barcelona: Ediciones Omega, 1956.

GEORGE, Pierre. A ação do homem. São Paulo: Difel; Difusão, 1968.

Sociologia e Geografia. Rio de Janeiro: Companhia Editora Forense, 1969.

HAESBAERT, Rogério. Regional-Global: dilemas da região e da regionalização na geografia contemporânea. Rio de Janeiro: Bertrand Brasil, 2010.

LE BOSSÉ, Mathias. "As Questões de identidade em Geografia Cultural - algumas concepções contemporâneas". In: CORRÊA, Roberto Lobato; ROSENDAHL, Zeny (orgs.). Paisagens, Textos e Identidade. Rio de Janeiro: EdUERJ, 2004.

LEFEBVRE, Henri. La Presencia y la Ausencia: contribución a la teoria de las representaciones. México: Fondo de Cultura Económica, 2006.

LEFF, Enrique. Racionalidade Ambiental: a reapropriação social da natureza. Rio de Janeiro: Civilização Brasileira, 2006.

LIMA, Elias Lopes de. A atualidade da luta de classes na modernidade tardia. Periferia. FEBF/UERJ, vol. 5, $\mathrm{n}^{\mathrm{o}}$. 2, pp. 1-21, 2013.

Encruzilhadas geográficas: notas sobre a compreensão do sujeito na teoria social crítica. Rio de Janeiro: Consequência, 2014.

MARX, Karl. Manuscritos Econômicos Filosóficos. São Paulo: Boitempo, 2004.

O Capital: crítica da economia política. Livro I: o processo de produção do capital. São Paulo: Boitempo, 2013.

MOREIRA, Ruy. Marxismo e Geografia: a geograficidade e o diálogo das ontologias. GEOgraphia, Niterói: PPGEO/UFF, ano VI, nº 11. pp. 21-37, 2004.

Socialidade e Espaço (as formas de organização geográfica das sociedades da era da Terceira Revolução Industrial - um estudo de tendências). Agrária. São Paulo: $n^{\circ}$. 2. pp. 93-108, 2005.

Pensar e Ser em Geografia: ensaios de história, epistemologia e ontologia do espaço geográfico. São Paulo: Contexto, 2007.

O Pensamento Geográfico Brasileiro: as matrizes clássicas originárias. São Paulo: Contexto, 2008.

PORTO-GONÇALVES, Carlos Walter. O Latifúndio Genético e a R-existência IndígenoCampesina. GEOgraphia. Niterói: PPGEO/UFF, ano IV, nº. 8, pp. 39-60, 2002.

Em Defesa dos Organismos Laboratorialmente Modificados - em busca da precisão conceitual. Observatório Latino-americano de Geopolítica. 2008. Disponível em <http://www.geopolitica.ws/media/uploads/Wporto4.pdf>. Acesso em: 20 outubro 2012.

QUAINI, Massimo. Marxismo e Geografia. Rio de Janeiro: Paz e Terra, 2002.

SANTOS, Milton. Por uma Geografia Nova: da crítica da geografia a geografia crítica. São Paulo: Hucitec/Edusp, 1978.

\section{6.}

A Natureza do Espaço: Técnica e Tempo. Razão e Emoção. São Paulo: Hucitec,

SMITH, Neil. Desenvolvimento Desigual: natureza, capital e a produção do espaço. Rio de Janeiro: Bertrand Brasil, 1988.

SOJA, Edward W. Geografia Pós-Modernas: a reafirmação do espaço na teoria social crítica. Rio de Janeiro: Jorge Zahar Editor, 1993. 
SORRE, Maximilien. "A Noção de Gênero de Vida e sua Evolução". In: MEGALE, Januário Francisco (org.). Max Sorre: geografia. São Paulo: Ática, 1984.

VÁZQUEZ, Adolfo Sánchez. Filosofia da Práxis. São Paulo: Expressão Popular, 2007.

VIDAL de LA BLACHE, Paul. Os Gêneros de Vida da Geografia Humana. GEOgraphia. Niterói: PPGEO/UFF, ano VII, nº. 13, pp. 113-130, 2005.

As Condições Geográficas dos Fatos Sociais. GEOgraphia. Niterói: PPGEO/UFF, ano IX, nº. 18, pp. 123-132, 2007.

WALlERSTEIN, Immanuel. Capitalismo Histórico e Civilização Capitalista. Rio de Janeiro: Contraponto, 2001. 